\title{
LÉRI'S PLEONOSTEOSIS, CARPAL TUNNEL COMPRESSION OF THE MEDIAN NERVES AND MORTON'S METATARSALGIA
}

\author{
Reginald Watson-Jones, London, England
}

There is no account in English literature of the dystrophy described by Léri as pleonosteosis (Gr. pleon-superabundant), which is characterised by broadening and deformity of the thumbs, flexion contracture of the fingers, thickening and stiffness of the toes, limited movement of other joints, shortness of stature and a Mongoloid facies. There are not more than twenty reports in the literature of the world, but it is difficult to believe that the incidence is represented accurately by such paucity of record. Four patients with typical contractures of the fingers and toes are described in this note. In one there was bilateral compression of the median nerves in the carpal tunnels and bilateral Morton's metatarsalgia with plantar digital neuromata. These complications of pleonosteosis have not been described before and they may be significant in the pathology of the disease.

\section{REVIEW OF LITERATURE}

The family reported by Léri included a man aged thirty-five years and the children of his second wife, a daughter aged four years and a son aged three weeks, who showed a familial and hereditary disorder which was not apparent at birth but became obvious during the first few years of life. The child by his first wife was normal.

The father measured only 5 feet 2 inches in height. His hands were broad and short, with accentuated skin creases between the thickened palmar pads. The thumbs were irregularly thickened and there was right-angled flexion deformity of the proximal interphalangeal joints of the fingers. Wrist movements were limited to a few degrees. The forearms were pronated and the elbows could not be extended fully. The arms were held slightly away from the trunk, in some internal rotation, and they could not be raised above the shoulder level. In the lower limbs there were similar though less pronounced changes, again bilateral and strictly symmetrical, with limitation of movement of the hip joints, fixed external rotation deformity, limitation of extension of the knee joints and slight genu valgum. The feet were short and "massive" and the toes broad and stiff.

Similar cases have been reported in French surgical literature (Comby 1922, Caussade and Peynet 1924, Crouzon 1924, 1929, Laroche and Barthes 1927, Rothéa 1927, Rouillard and Barreau 1927, Rousseau et al. 1928, Cohen and de Herdt 1928, Apert 1931, Hallé and Apert 1931, Feiguine and Tikhodéeff 1932, and Rocher et al. 1932, 1946, 1947). There are two reports from South America (Valentin 1939, Gareiso et al. 1946), but no others have been traced. The constant feature has been the curious thickening and broadening of the digits, especially the thumbs, with flexion contracture of the interphalangeal joints. Changes in the proximal joints have varied. In some there was limitation of elbow and shoulder movement, or increase in size of the femoral heads with coxa vara; in many there was slight genu valgum, one patient needing two operations for the correction of this deformity; but in others the elbow, shoulder, hip and knee joints were normal. Most, but not all, patients showed the Mongoloid facies. The influence of heredity was usually obvious, but sporadic cases were reported by Laroche and Barthes, Rocher and Roudil, and Rocher and Pesme.

Occasional features may perhaps be ignored; for example, there was evidence in one patient of congenital syphilis (Laroche and Barthes), in one of tuberculosis (Feiguine and Tikhodéeff), in two of corneal opacity (Rocher) and in two of enlargement of the sella turcica (Rocher et al.). Impairment of intellect was noted only by Cohen and de Herdt, and by Rocher and Roudil. In the family reported by Apert there was mental deficiency, but the diagnosis of pleonosteosis may be in doubt because although there was contracture of the fingers, all three patients suffered from delayed speech and from progressive deafness and cachexia, and they all died in childhood. 
Leri was impressed by the bene changes, patticularly the large epiphyses and thick metaphyses of the phalanges and metacarpals. He thought that excessive epiphysial development was the characteristic feature and that this accounted for the postural abnormality and limitation of joint movement. He was supported by Rocher and Roudil in their report of an infant who was observed for three years from the age of twenty-six days-the youngest recorded patient. The centres of ossification in the femur, tibia and tarsus corresponded at birth to those of an infant aged six to twelve months; but the centres of ossification for the metacarpal bones were unusually delayed. In other reported cases all centres of ossification appeared at the normal date (Hallé and Apert).

The short, broad, thick hands and feet, the limited extension of knees and elbows, and the fixed internal rotation of the upper limbs and external rotation of the lower limbs, suggested to Léri an atavistic return to the simian attitude. He pointed out that it was only in the third or fourth month of intra-uterine life that the limbs began to rotate so that the patella would be in front of the knee joint and the olecranon behind the elbow joint. Léri wrote: " the characteristics of pleonosteosis approach closely those of the Mongolian racethe mother of all human races-and they are indeed a reversion to an atavistic race." But the Mongols show no skeletal abnormality; not all patients with pleonosteosis have a Mongoloid facies; and many patients with advanced contracture of the fingers and toes have no deformity of the limbs and no resemblance at all to the simian attitude. Was Léri right?

\section{CASE REPORTS}

Case 1. P. L., female, aged 21 years, farm worker-Flexion deformity of the fingers of both hands was noticed in early life and increased steadily (Fig. 1). At the time of examination, in cold weather, there was a tendency to cyanosis of the hands; and it was thought that there might be slight wasting of the thenar and first dorsal interosseous muscles. Radiographs showed buttress enlargement of the seventh cervical transverse processes, and the disability was attributed to the costo-clavicular syndrome.

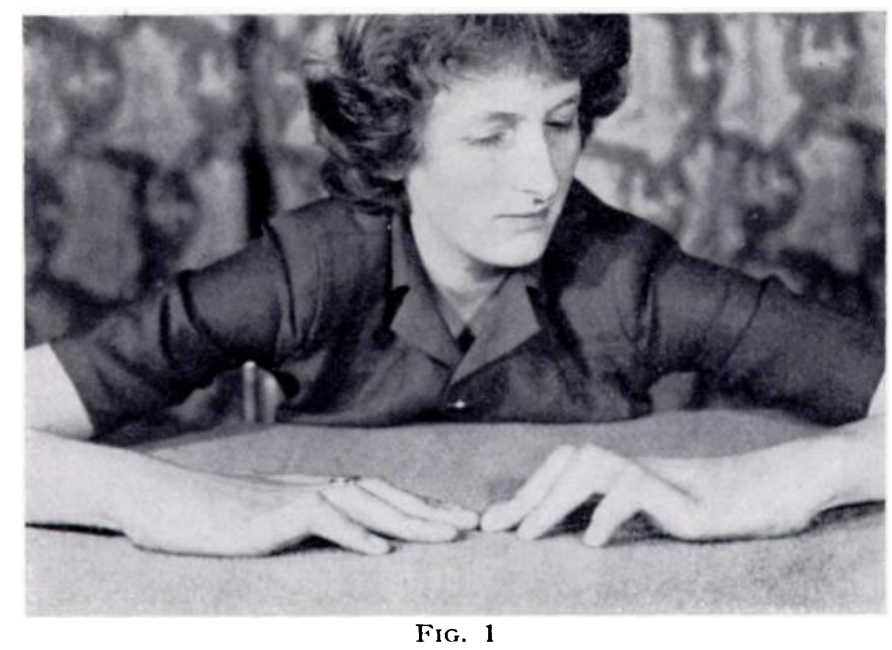

Case 1. Flexion contracture of the proximal interphalangeal joints. Despite the normal facies, the diagnosis of pleonosteosis was established by broadening of the thumbs, similar deformities of the toes, significant changes in the proximal joints, and comparable deformities in the mother, aunt, great-aunt and great-grandmother.

Four years later it was reported that the deformities had increased, and provisional arrangements were made for exploration of the supraclavicular triangles of the neck. Further examination then disclosed features that should, no doubt, have been observed long before. There was not only flexion contraction of the proximal interphalangeal joints but also broadening of the thumbs. The toes showed similar flexion

VOL. $31 \mathrm{~B}$, No. 4 , NOVEMBER 1949 
contractures. In the shoulders and hips there was slight limitation of rotation. Examination of the patient's mother (Case 2, Mrs 1., aged 53 years) disclosed that she too had hroad thumbs and flexion deformity of the fingers and toes, though of less degree. The patient's aunt (Case 3, Mliss (i. F., aged 51 years) had flexion deformity of the interphalangeal joints of both hands and " hammer toes." Two of the patient's great-aunts and her great-grandmother had been proud of " the Bridge hand "; this referred to the family name and not to the game; they all had flexion deformity of the interphalangeal joints. Comment-The youngest member of this family narrowly escaped exploration of the neck for excision of "the fibrous remnants of cervical ribs" but there can be little doubt that she and her maternal relatives showed, in attenuated form, the contractures and deformities characteristic of pleonosteosis. It is true that changes in the proximal joints were minimal and that, far from the facies being Mongoloid, the patient was very attractive; but we know from the literature that these features are not essential to the syndrome of pleonosteosis.

Case 4. J. D. H., male, aged 20 years, forester-Family history--Parents and grandparents normal. Only sister normal. No brothers.

History - He was apparently normal at birth. In childhood his schoolmates laughed because he could not point with a straight finger; and this deformity is shown in early photographs. He learned to write with a pencil held between the index and middle fingers, and in due course he graduated at a University. The deformities of fingers and thumb increased steadily.

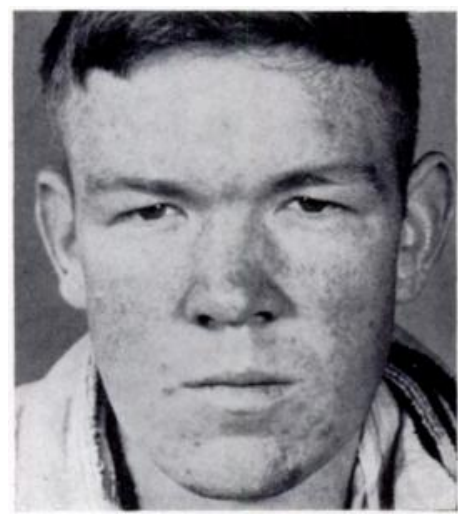

FIG. 2

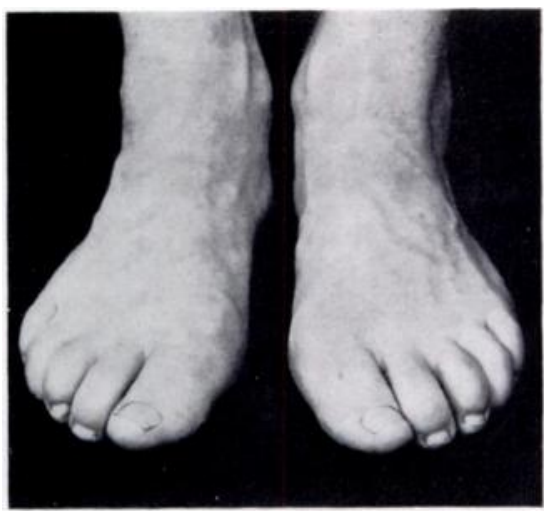

FIG. 3

Case 4. The facies are Mongoloid with a broad, flat nose and typical curve at the inner canthus (Fig. 2). The toes are broad and contracted like the fingers (Fig. 3).

In recent years he had noticed numbness, tingling and pins-and-needles in the index and middle fingers of both hands. He could seldom sleep for more than six hours. After a strenuous day of harvesting or after rowing, he would wake in the early morning with intense pain in the fingers and hands. If he had been particularly energetic the pain spread up the forearms almost to the elbows.

Three years ago he noticed pain in the left fourth toe when wearing shoes. If he kept the shoe on, the pain spread; but if he took it off, the pain disappeared and he could then put it back and keep going for half an hour. Tingling and numbness were felt in the toe, and pressure under the fourth metatarsal head caused "clicking." The symptoms were worse in warm weather. There were no symptoms in the right foot.

Clinical examination-In intelligent, powerfully built man of short stature ( 5 feet 4 inches). Face broad and square; bridge of nose wide and flattened; eyes set apart with Mongolian curving of the upper eyelid at the inner canthus (Fig. 2). Hands short and square. Thumbs broad and thick with valgus deformity of the interphalangeal joints and slight varus deformity of the metacarpo-phalangeal joints (Figs. 4 and 5 ). Thenar eminences thickened with accentuation of the palmar creases (Fig. 7). Fingers - flexion contracture of all joints; 90 degrees at the distal joints, 40 degrees at the proximal interphalangeal joints, 30 degrees at the metacarpo-phalangeal joints; the deformity remained the same no matter what the position of the wrists, showing that the contractures were due to capsular and not tendon shortening. Radiographs showed thickening of the shafts of the metacarpals and phalanges but no significant bone deformity of the joints (Fig. 6). Wrist joints-thickening of periarticular tissues; dorsiflexion limited to 20 degrees and palmar-flexion to 30 degrees. Radiographs showed obliquity of the lower radial articular surface, and 


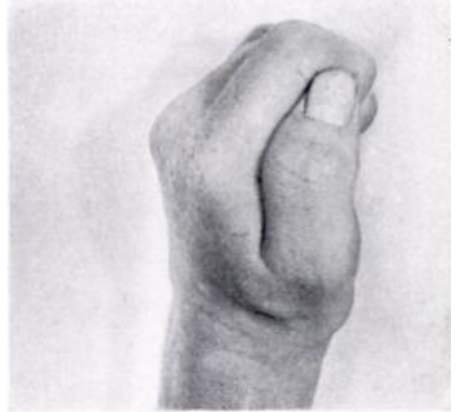

FIG. 4

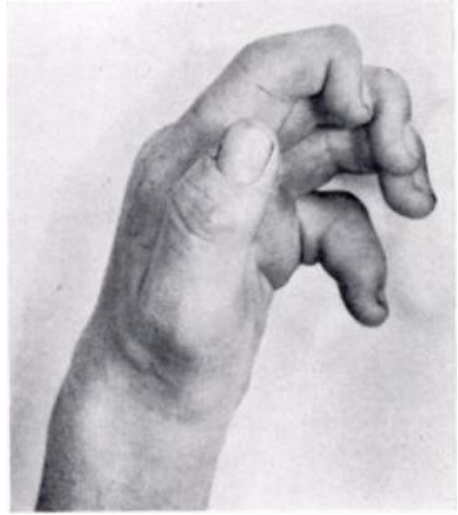

FIG. 5

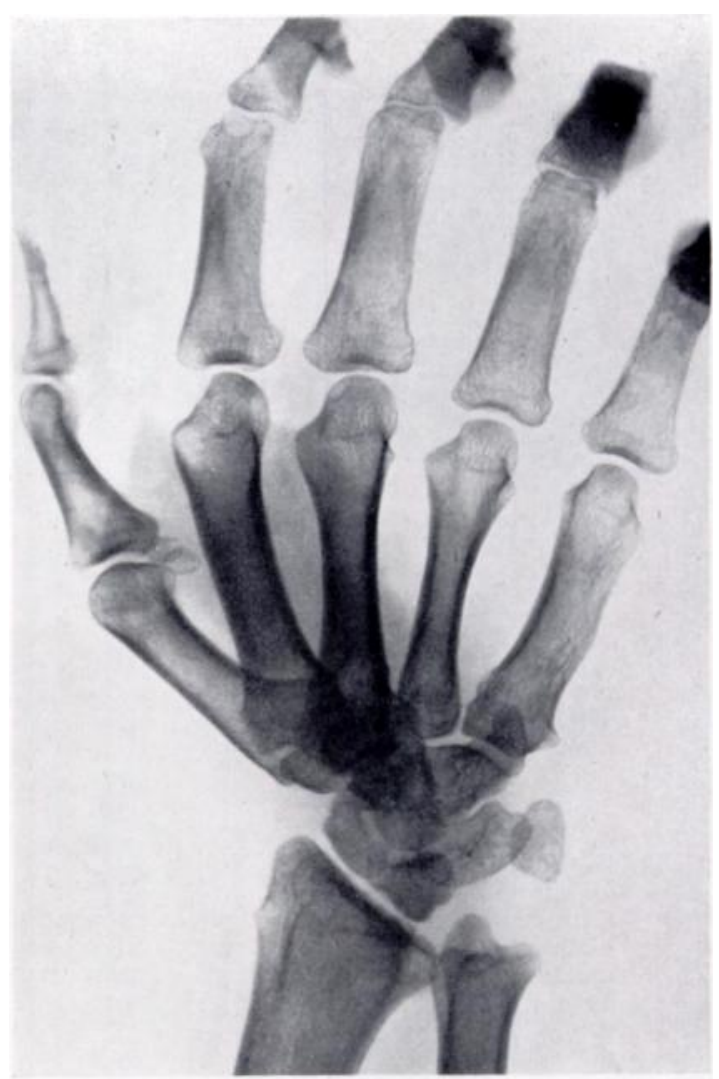

FIG. 6

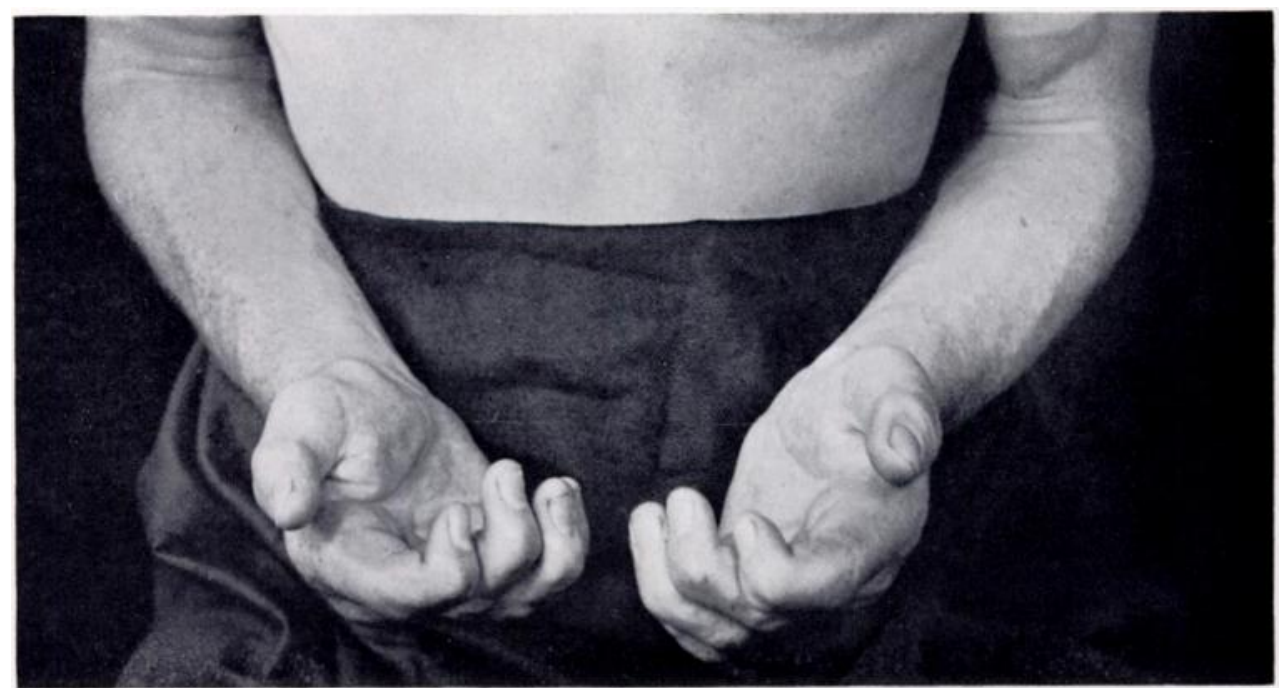

FIG. 7

Case 4. Typical case of pleonosteosis. Photographs of the left hand in full flexion (Fig. 4) and full extension (Fig. 5) demonstrate the limited movement, contracture of interphalangeal joints, and deformity of the thumb. The radiograph shows thickening of the metacarpals and phalanges but not sufficient bone change to cause joint contracture (Fig. 6). The accentuated palmar skin creases, and the limitation of supination of the forearms, are shown in Figure 7. 


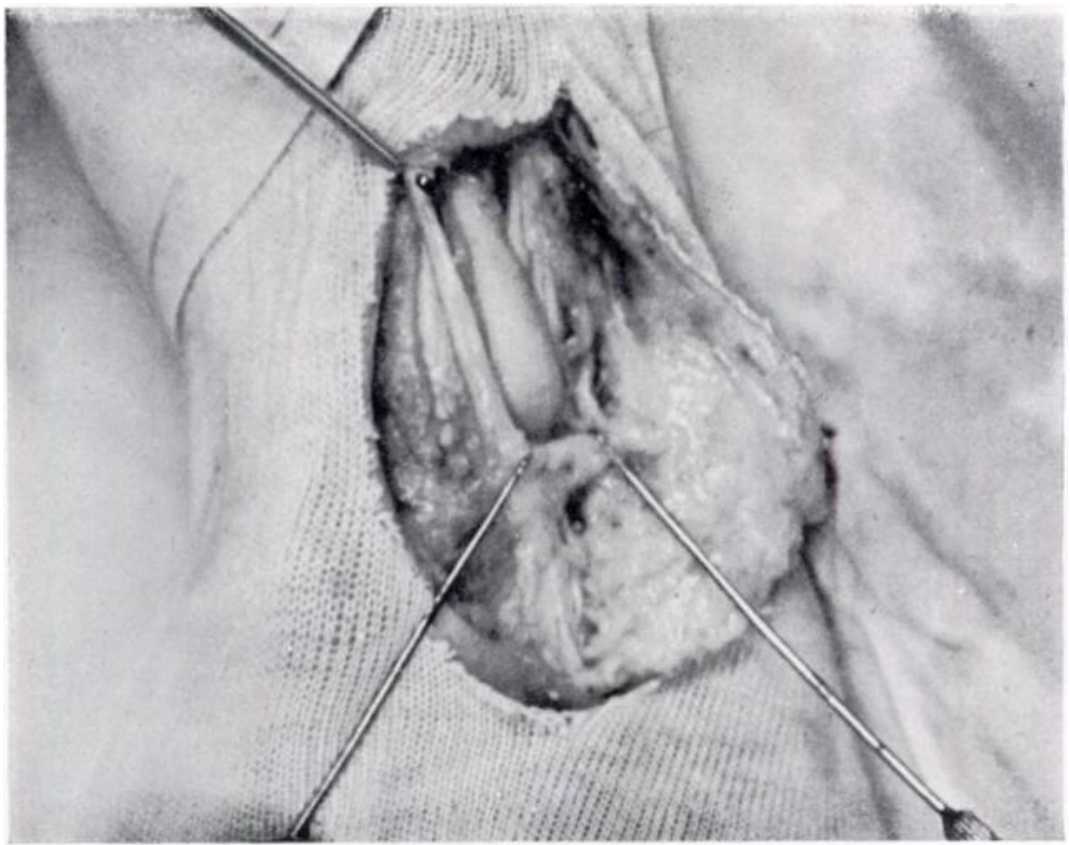

FIG. 8

Case 4. Exposure of the median nerve at the wrist joint (right). The upper hook is retracting palmaris longus. The lower hooks are at the proximal margin of the anterior carpal ligament. The median nerve is expanded to a neuroma 11 millimetres in diameter. The normal nerve above measures 7 millimetres.

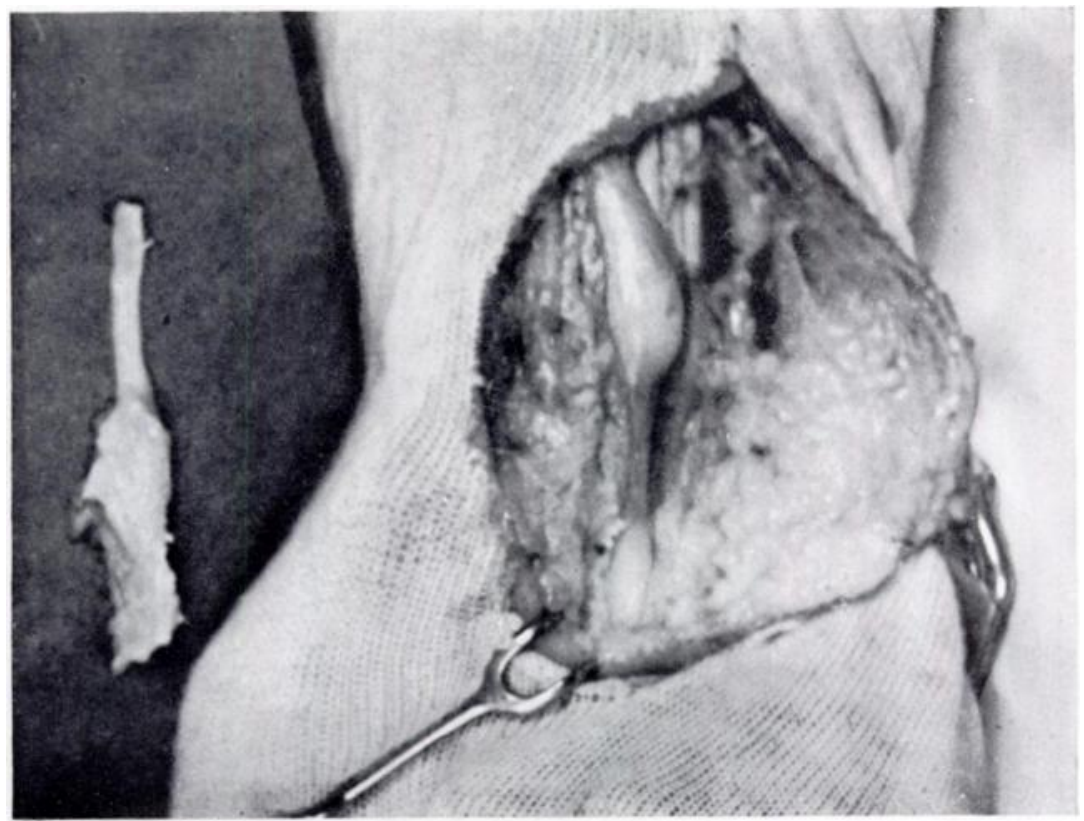

FIG. 9

Case 4. The anterior carpal ligament has been excised together with part of palmaris longus (specimen on left); it was three times its normal thickness. Beneath it the median nerve was discoloured and attenuated, measuring only 3 millimetres. The operative findings in the left wrist were identical. 
slight relative shortening of the ulna, but no thickening of the joint margins, no osteophytes and no abnormality of the carpal bones. Median nerves-In both hands there was loss of touch and alteration in the quality of pain over most of the digital part of the median supply. No wasting or paresis of the intrinsic muscles. Sensation in the ulnar distribution normal. Other joints of the upper limbsPronation of the forearms limited to 30 degrees and supination to 40 degrees. Movement of the elbow joints normal. Shoulder joints normal except for slight limitation of external rotation. Clavicles, skull, spine and pelvis normal. The lower limbs-Internal rotation of the hip joints 20 degrees, external rotation 40 degrees, other movements normal. Radiographs showed wide femoral necks. Knee and ankle joints normal. Feet-short and broad, 9.5 inches long, 4 inches wide; the shoes were two sizes larger than needed for the length of the foot. Great toes short and thick like the thumbs; slight valgus deformity at the terminal joints. Flexion contracture of all toes, to the right-angle at the terminal interphalangeal joints (Fig. 3). Transverse arches flattened. Plantar digital nevves-Tenderness on pressure over the bifurcation of the digital nerve to the cleft between third and fourth toes. No neuroma felt. No objective change in sensation. General condition-He was seen by Sir Henry Cohen who excluded abnormality of the central nervous system, found no metabolic change on detailed blood examination, and established the diagnosis of Léri's pleonosteosis.

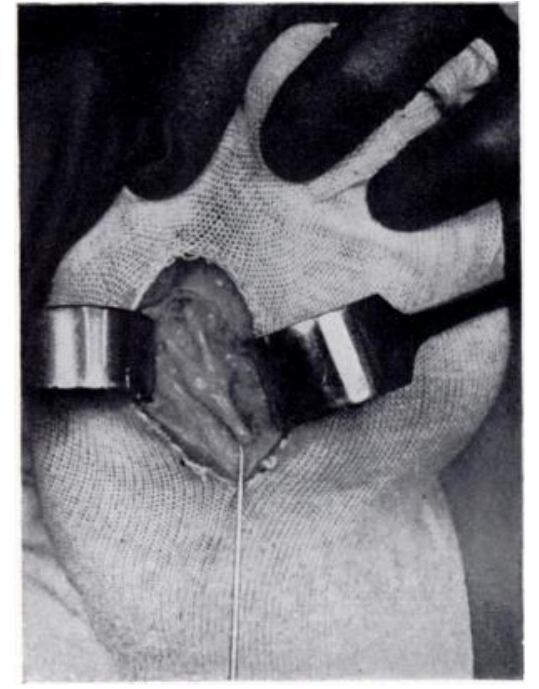

FIG. 10

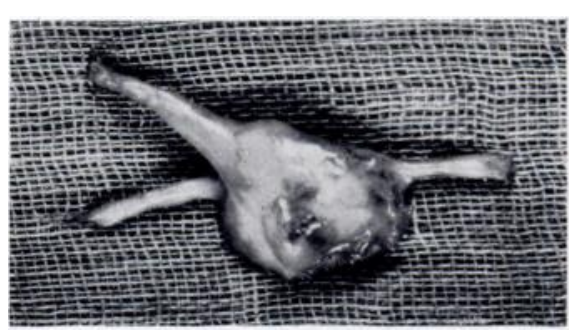

FIG. 11

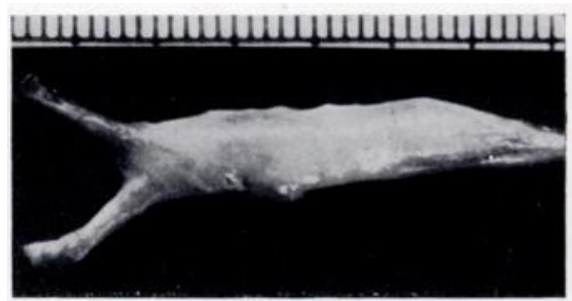

FIG. 12

Case 4. Plantar digital neuroma at the third-fourth cleft. In the right foot (Figs. 10-11) there was an eccentric neuroma with thickening of the branch to the fourth toe-to which pain was referred. The neuroma from the left foot was more diffuse (Fig. 12-scale in millimetres).

First operation, September 1947-Resection of both anterior carpal ligaments with neurolysis of median nerves; excision of plantar digital neuroma (left)-The median nerves were exposed (right, Mr Raymond King; left, R. W-J.). Immediately above each carpal tunnel the nerve was expanded over a distance of 2 centimetres to form a neuroma 11 millimetres in diameter; the normal nerve above measured 7 millimetres (Fig. 8). The anterior carpal ligament was resected. It was much tougher and three times thicker than normal. Deep to the ligament, the nerve was obviously compressed and attenuated, measuring only 3 millimetres in diameter; it had lost its normal sheen and appeared discoloured (Fig. 9). Immediately distal to the ligament, the nerve regained its normal appearance and again measured 7 millimetres.

Through a plantar incision the digital nerve to the third-fourth cleft was exposed. Just proxinnal to its bifurcation, and lying over the transverse ligament, was a neuroma three times the normal diameter of the nerve and almost 3 centimetres long (Fig. 12). The nerve and neuroma were excised. The plantar digital vessels were not recognised.

Second operation, September 1948-Excision of plantar digital neuroma (right)-During the previous year the patient complained increasingly of symptoms in the right foot, exactly similar to those in the left. The first attack occurred while wearing hobnail boots, and two others coincided with the first wearing of new shoes. The digital nerve to the third-fourth cleft was exposed and a neuroma was removed (Figs. 10 and 11). It was similar to the one removed previously except that it was eccentric and involved a 
shorter length of nerve. It showed a fibrous swelling extending from the digital nerve itself into the branch to the fourth toe, but not to that for the third toe. This finding corresponded with the reference of pain to the fourth but not to the third toe.

Progress-Pain in the hands was relieved within a few days of the first operation but impairment of sensation persisted for twelve months before recovery was complete. In each foot, relief of pain was gained promptly after operation. Now, after two years, although the deformities of the hands and feet are the same, he does full work as a forester and often walks fifteen miles a day over peat-bogs and sand-dunes.

Pathological report (Professor Dorothy Russell, Bernhard Baron Institute of Pathology, London Hospital).

1) Anterior carpal ligament-The specimen consists of a strip of the palmaris longus tendon to which is attached a mass 3.8 centimetres long and 1.2 centimetres thick, of tough, grey tissue corresponding to the anterior carpal ligament. Macroscopically, it is abnormally thick. A control specimen measures up to 0.4 centimetres thick; this normal anterior carpal ligament is composed of closely woven bundles of rather acellular collagenous tissue containing scanty elastic fibres which collectively form a layer, up to $0 \cdot 1$ centimetres thick, bordering the smooth inner surface of the carpal tunnel. Superficial to this surface the collagen bundles ramify through a zone of adipose tissue which includes vessels of supply and small bundles of nerve fibres; and this layer is also intersected by bundles of stout elastic and finer collagen fibres (Fig. 13). The pathological specimen-The collagenous tissue is greatly increased, forming almost the whole of the section. A large proportion is actually fibrocartilage, in association with which a good deal of mucinous material is laid down both in relation to the cells and in linear deposits between the collagen fibres. There is a remarkable absence of elastic tissue in comparison with the control (Figs. 14 and 15). A small amount of skeletal muscle is attached to the surface; this shows advanced atrophy of the fibres and associated fibrosis. The tendon appears normal. There is no demonstrable vascular abnormality. Two twigs of nerve at the periphery of the specimen show early mucinous change and fibrous increase of the endoneurium.

2) Plantar digital neuroma-The excised portion of digital nerve forms a fusiform mass $3 \cdot 7$ centimetres long and up to $\mathbf{0 . 5}$ centimetres thick. A longitudinal section shows wide separation of the constituent nerve bundles by collagenous tissue of variable density containing evenly distributed spindle fibroblasts and small vessels, mainly arterioles and venules. There is no inflammatory cellular infiltration apart from one small group of perivascular lymphocytes. Tissue mast-cells are scattered throughout the collagenous tissue. Several of the nerve bundles appear greatly swollen from the presence of mucin, especially in the endoneurium, and from uneven fibrous thickening of this tissue and of the perineural sheaths. A few tissue mast-cells are present. In the more swollen bundles the axis-cylinders, demonstrated by Bielschowsky's method, are parallel but widely separated. The presence of occasional amoeboid macrophages suggests that some have undergone degeneration and have disappeared; but stages of this process are not demonstrable. None of the blood vessels in this preparation shows degeneration or any occlusive change.

3) Summary-The digital neuroma is of the ischaemic type such as may occur in cases of Volkmann's contracture, but the specimen does not provide evidence of the cause of the ischaemia. The anterior carpal ligament is greatly thickened by fibrocartilaginous alteration of the collagen. This may reasonably have produced compression and atrophy of adjacent structures. If a similar change is widely spread in other ligaments the digital neuroma might be attributable to this.

\section{DISCUSSION}

Pathology of pleonosteosis-Léri believed that the pathological basis of this disorder was premature and excessive ossification with epiphysial enlargement accounting for deformity. The title he chose leaves no doubt as to his view but it is an unfortunate title. Despite the support of Rocher and Roudil, there has been no general evidence of "precocity of ossification." Moreover, the contracture of joints has always been far greater than would be expected from the relatively limited bone change. This was evident in all four patients in this series; even in Case 4, the thickening of the metacarpals and phalanges was not associated with bone change at the joints sufficient to account for right-angled flexion deformity.

There have been no previous studies of the ligaments and capsules in pleonosteosis. The evidence now available shows that, in at least one case, there was striking change in the carpal ligaments which were short, thick, lacking in elastic fibres, and largely changed to fibrocartilage. When this is correlated with the clinical observation that the deformities were due mainly to capsular contraction, it seems possible that the primary pathological change in pleonosteosis may be in the joint ligaments, and that the bone thickening may be due to periosteal traction at their metaphysial attachments. 


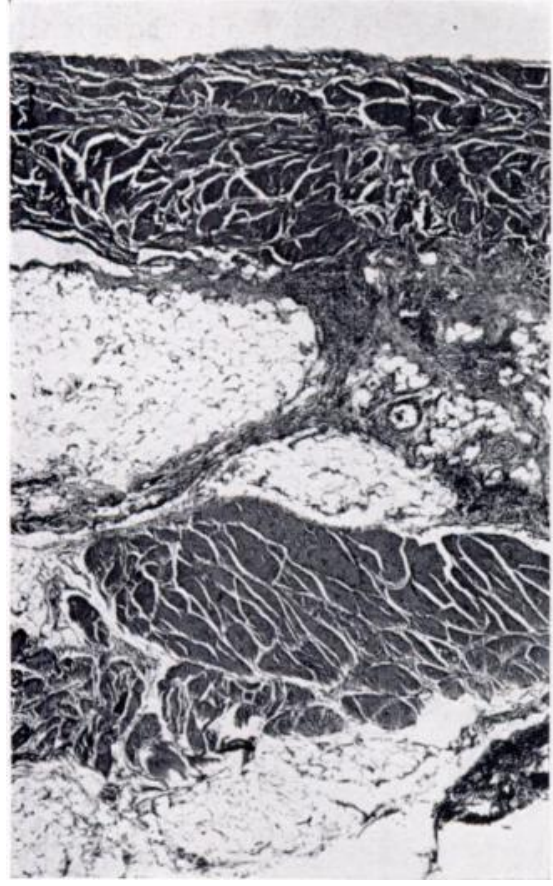

FIG. 13

Whole thickness of the anterior carpal ligament in a normal wrist, serving as control (haematoxylin and van Giesen, $\times 27$ ).

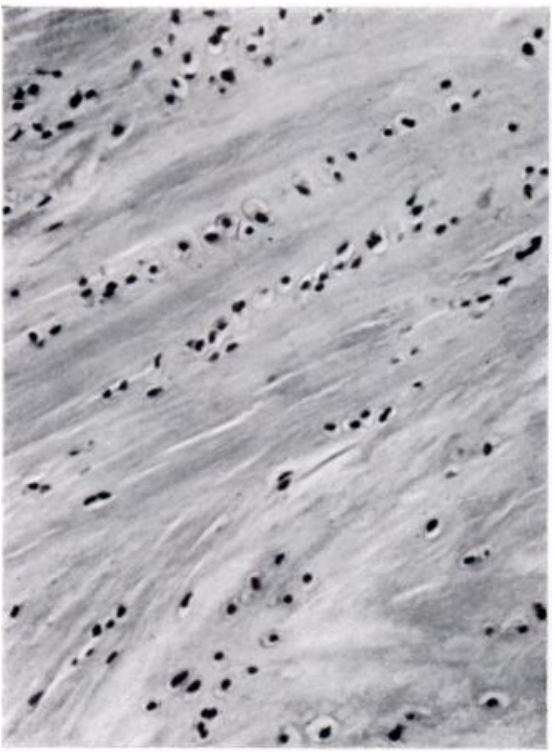

FIG. 15

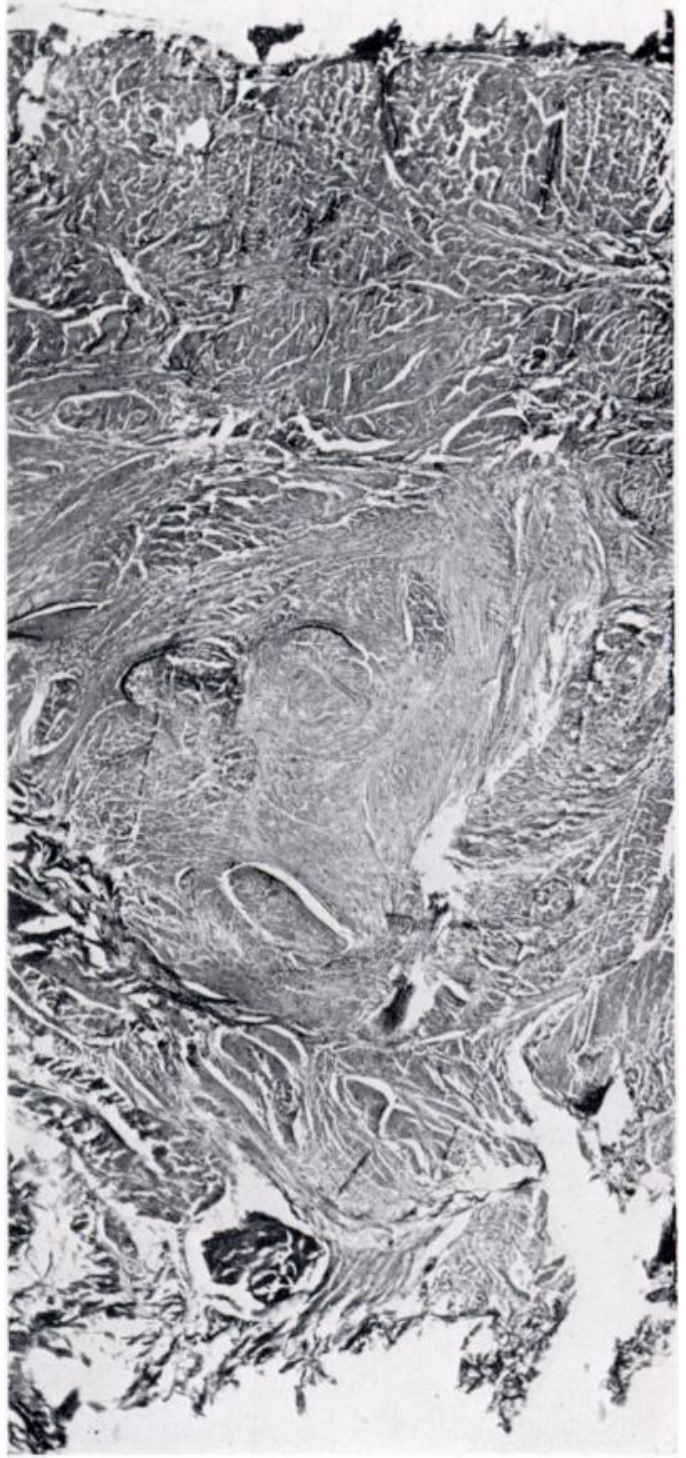

FIG. 14

Whole thickness of the anterior carpal ligament in Case 4 (pleonosteosis with carpal tunnel compression of median nerve). The preparation has the same magnification and is stained in the same way as in the control specimen in Figure 13 (haematoxylin and van Giesen, $\times 27$ ). There is great increase in the collagenous tissue; much of it is actually fibrocartilage, which is seen in higher magnification in Figure 15 (haematoxylin and eosin, $\times 150$ ). 
Léri and other writers were at pains to distinguish pleonosteosis from achondroplasia which of course it does not resemble. A closer analogy could be drawn with arthrogryposis multiplex congenita, in which there are congenital and hereditary tendencies, sometimes a Mongoloid facies, and more severe joint contractures due solely to changes in the soft tissues (Middleton 1934). But we have only begun to study the pathology of this disease and many further investigations are needed.

Carpal tunnel compression of the median nerve-Injury to the median nerve at the wrist by the pressure of a dislocated bone or displaced fracture has long been recognised, and " tardy median palsy" occurring many years after fracture has been described. Recently there have been reports of compression of the nerve in a carpal tunnel that was normal, or, at least, not encroached upon by bone thickening. There are two records of nerve compression at this level in patients with acromegaly. These nerve lesions have often been grouped together, but it would be wise to differentiate them.

Acute compression by bone-The fact that median paralysis seldom complicates recent fractures of the lower end of the radius even when widely displaced, but that it often occurs when the semilunar bone is dislocated forwards, indicates the susceptibility of the nerve to compression within the confined space beneath the anterior carpal ligament.

Acute compression by haemorrhage - In 1943 this writer mentioned the case of a doctor who stopped a fast cricket ball in the palm of his hand. After two hours he felt tingling and then intense pain in the distribution of the median nerve. The lightest touch on the fingers precipitated agonising waves of pain. Aspiration of sixteen cubic centimetres of blood from the palm gave temporary relief but it was not until the anterior carpal ligament had been divided that the agony was relieved. The ligament itself was normal and there was no bone injury. The median paralysis, which recovered after several months, was due to acute compression in the tunnel by haemorrhage.

Slow compression by bone-There are many accounts of late median palsy due to compression of the nerve by displaced bone fragments, or by the osteophytes of hypertrophic arthritis from old carpal injuries. In two patients reported by Zachary (1945) the injury had been a fracture of the carpal scaphoid bone; the median paralysis recovered after section of the anterior carpal ligament by Seddon. Cannon and Love (1946) described eight patients with median neuritis due to deformities of the carpal bones from fractures sustained twenty to fifty years before. In one of the three cases reported by Newman (1948) a fracture of the scaphoid bone was complicated by median paralysis after an interval of twenty years. In these and other records the neuritis has been of ischaemic origin, due to compression of the nerve by bone thickening in the floor of the tunnel, and relieved by division of the anterior carpal ligament with decompression of the nerve. Other accounts of tardy median palsy include cases that were not true examples of carpal tunnel compression, the fracture being in the lower end of the radius (Paget 1863, Lewis and Miller 1922, Abbott and Saunders 1933).

Slow compression by occupational strain-Moersch (1938) reported one patient with no bone deformity whose median nerve paralysis was relieved by section of the ligament. Cannon and Love (1946), in their series of thirty-eight cases included three with median palsy of spontaneous origin without radiographic evidence of bone abnormality. Brain, Wright and Wilkinson (1947) described six women with bilateral median neuritis, all in the second half of life, and in all of whom the wrist bones were normal. Operative exposure showed a neuroma of the median nerve immediately proximal to the anterior carpal ligament with flattening of the nerve beneath it. Similar cases have been reported by Newman (1948) and others. Brain and Wright believed that the carpal tunnel was normal and that the palsy was due to occupational stress. They showed that, in a cadaver, pressure in the tunnel was three times greater when the wrist was fully extended than 
when it was flexed, and pointed out that many household occupations were performed with an extended wrist. They surmised that postural strain alone caused pressure on the nerve, degeneration in the artery to the nerve, and oedema of the nerve which increased the pressure still more.

The influence of occupation is undoubted. The neuritis may occur in any worker " whose business entails grasping instruments for long periods or pressing them into the ball of the thumb" (Kinnear Wilson 1940). But it is unfortunate that in none of these contributions was there a pathological study of the anterior carpal ligament. Is it right to assume that simple postural strain may cause paralysis of a normal median nerve lying in a normal carpal tunnel? It would seem more likely that occupational stress and advancing age cause thickening of the anterior carpal ligament and that this is the source of compression of the nerve. The possibility gains support from Case 4 in this series.

Slow compression by thickening of the anterior carpal ligament-Case 4 shows clear evidence of compression of the median nerve by an abnormally thick carpal ligament. Two other reports may be significant. Woltman (1941) described an acromegalic patient with median paralysis which recovered after division of the anterior annular ligament. Cannon and Love (1946) reported another patient with acromegaly who gained relief from pain and paraesthesia in the median distribution of the hand by division of the ligament. Woltman said that the nerve was compressed in front of the wrist joint "by proliferation of tissues." *

It may be, of course, that carpal tunnel compression of the nerve by ligamentous thickening is peculiar to certain constitutional diseases. But before accepting the suggestion of Brain, Wright and others that simple postural strain is an additional cause of compression of the median nerve at the wrist, detailed pathological studies of the ligament whenever it is removed for tardy median palsy should be reported.

Plantar digital neuroma and metatarsalgia-In many patients, pain under the tread of the foot arising from walking or long standing, usually referred to the fourth toe but sometimes to the third or even second toes, often associated with numbness and tingling, and nearly always relieved by removing the shoe, is still being attributed to " anterior flat foot " and treated unsuccessfully by metatarsal pads and exercises. Betts (1940) demonstrated that there was fibrous swelling of the digital nerve and that the symptoms were relieved by resecting the neuroma. In a recent study, Nissen (1948) in collaboration with Holmes, showed that the nerve lesion is ischaemic in nature and that severe degenerative changes in the digital artery precede the marked increase of connective tissue that provides the main bulk of the nerve expansion.

The typical neuromata removed from the digital nerves to the third-fourth cleft in each foot of Case 4 may have been coincidental, or due to no more than that the contracted toes were associated with flattening of the transverse arches with consequent weight-bearing injury to the digital arteries and nerves. But there is evidence to show that the digital neuritis of metatarsalgia is not related to transverse flat foot or to weight-bearing injury. The primary lesion is certainly in the digital artery. Nissen (1948) indicated the importance of the narrow fibrous tunnel at the proximal margin of the transverse metatarsal ligament through which the digital artery must pass to enter the cleft. It is not yet known why the digital artery to the third-fourth cleft should so often show the degenerative change, or why a similar lesion should arise less commonly in other clefts. But Nissen's observations indicate that the vascular supply to the plantar digital nerves should be studied in more detail. In Case 4 it seems possible that the ischaemic nerve lesions in the feet were due to compression of the digital arteries by abnormal plantar ligaments, comparable to the proved compression of the median nerves by abnormal carpal ligaments.

* In acromegaly there may also be plantar digital neuritis with neuroma formation (Nissen-personal communication).

vol. $31 \mathrm{~B}$, No. 4, NOVEMBER 1949 


\section{SUMMARY}

1. Léri's pleonosteosis is characterised by broadening and deformity of the thumbs and great toes, flexion contracture of the interphalangeal joints, limited movement of other joints, and often a Mongoloid facies. Four such cases are described.

2. A review of the twenty reports in the literature, and the cases now described, shows that the deformities are due to capsular contracture rather than deformity of bone.

3. In one patient there was striking evidence of fibro-cartilaginous thickening of the anterior carpal ligaments. It is suggested that the primary pathological change in pleonosteosis may be in the joint capsules rather than in the epiphyses.

4. The patient with thickening of the anterior carpal ligaments had bilateral median palsy from carpal tunnel compression.

5. The causes of carpal tunnel compression of the median nerve are reviewed. Acute compression may be due not only to dislocation of the semilunar bone but to haemorrhage in the palm. Late compression by bone may occur twenty to fifty years after injury. Late compression without bone abnormality has been attributed to occupational stress, but it is suggested that pathological thickening of the anterior carpal ligament may be the cause.

6. The patient with pleonosteosis and bilateral median palsy had also bilateral Morton's metatarsalgia with large digital neuromata.

7. Plantar digital neuritis has already been shown to be an ischaemic nerve lesion preceded by degenerative changes in the digital artery. The significance of the fibrous tunnel through which the artery passes to reach the digital cleft is considered.

I am grateful to Professor Dorothy Russell for her co-operation; to Sir Henry Cohen whose aid in Case 4 was invaluable; to Mr Raymond King and my other colleagues at the London Hospital; and to Mr Ruddick, clinical photographer, and Mr John King who prepared the micro-photographs.

\section{BIBLIOGRAPHY OF LÉRI'S PLEONOSTEOSIS}

APERT, E. (1931): Maladie familiale caractérisée par des épaississements osseux rappelant la pléonostéose, par une surdité progressive, et par une déchéance intellectuelle et physique conduisant à une issue fatale. Bulletin de la Société de Pédiatrie de Paris, 29, 498.

Caussade, G., and Peynet, J. (1924): Un cas de pléonostéose familiale. Bulletins et Mémoires de la Société Médicale des Hôpitaux de Paris, 48, 210.

Cohen, and de Herdt (1928): Pléonostéose familiale. Journal de Neurologie et de Psychiatrie, $28,395$. (Abstracted in American Journal of Diseases of Children, 1929, 38, 173.)

Сомву, J. (1922): La pléonostéose familiale. Archives de Médecine des Enfants, 25, 360.

Crookshank, F. G. (1924): Quoted by Léri in the words: “ A Londres, M. Crookshank, médecin de l'hòpital français, avait examiné une femme qui présentait des déformations assez charactéristiques; le père et deux enfants de cette femme auraient des difformities semblambles.

Crouzon, O. (1924): Pléonostéose familiale (dystrophie osseuse, généralisée, congénitale et héréditaire), in Nouveau Traité de Médécine; edited by G. H. Roger, F. Widal and P. J. Teissier. Paris: Masson et Cie. Fascicule 22, pp. 214-217.

Crouzon, O. (1929): Pléonostéose familiale (dystrophie osseuse généralisée, congénitale et héréditaire), in his Etudes sur les Maladies Familiales Nerveuses et Dystrophiques. Paris: Masson et Cie, pp. 371-374. Feiguine, E., and TiкнодÉEF, S. (1932): Un case rare d'ostéopathie systématisée-un cas de pléonostéose en U.R.S.S. Archives de Médecine des Enfants, 35, 654.

Gareiso, A., Vijnovsky, B., and Pellerano, J. C. (1946): Léri's familial pléonostéosis. Revista de la Asociación Médica Argentina, 60, 323.

Hallé, J., and Apert, E. (1931): Pléonostéose familiale d'André Léri (Présentation de Malade). Bulletins de la Société de Pédiatrie de Paris, 29, 492.

Laroche, G., and Barthes (1927): Un cas de pléonostéose chez un hérédo-syphilitique. Bulletins et Mémoires de la Société Médicale des Hôpitaux de Paris, 51, 459. (And also in Archives de Médecine des Enfants, 1927, 30, 460.)

LÉRI, A. (1921): Une maladie congénitale et héréditaire de l'ossification: La pléonosténse familiale. Bulletins et Mémoires de la Société Médicale des Hôpitaux de Paris, 45, 1228. 
LÉRI, A. (1922): Dystrophie osseuse généralisée congénitale et héréditaire: La pléonostéose familiale. La Presse Médicale, 30, 13. (Reference in this article to personal communication from Crookshank, London, reporting a family with Mongoloid facies.)

LÉRI, A. (1924): Sur la pléonostéose familiale. Bulletins et Mémoires de la Société Médicale des Hôpitaux de Paris, 48, 216.

LÉRI, A. (1926): Les affections des os et des articulations. Paris: Masson et Cie, 5-34.

Marfan, A. B. (1926) : L'imbécillité Mongolienne. Presse Médicale, 34, 1377.

MASSART, R., and BoHN, A. (1926): Malformations osseous congénitales multiples. Bulletins de la Société de Pédiatrie de Paris, 24, 388. (Reporting not a case of pleonosteosis but a similar condition, and drawing attention to the points of difference, with comments by Léri.)

Rocher, H. L. (1947): La pléonostéose (maladie de Léri). Revue d'Orthopédie et de Chirurgie de l'Appareil Moteur, 33, 24.

Rocher, H. L., and Roudil, G. (1932): La pléonostéose (maladie de Léri). Etude Anatomo-clinique et Radiographique, Bordeaux Chirurgical, 4, 359.

Rocher, H. L., and Pesme, P. (1946): Un cas de pléonostéose (maladie de Léri) avec Cornées Opalescentes. Journal de Médecine de Bordeaux, 123, 121.

RothéA, M. (1927): La pléonostéose familiale (naladie d'André Léri) Thèse, Paris, Nancy, No. 421, pp. 62. Rouillard, J., and BARREAU, P. (1927): Un nouveau cas de pléonostéose héréditaire avec atteintes graves des grosses articulations. Bulletins et Mémoires de la Société Médicale des Hôpitaux de Paris, 51, 794 (and also in Archives de Médecine des Enfants, 1927, 30, 657).

Rousseau, Rouillard, J., and Barreau, P. (1928): Double cas de pléonostéose familiale. Bulletins et Mémoires de la Société de Radiologie médicale de France, 146, 51.

VAlentin, B. (1939): Malformations of the locomotor apparatus-Arachnodactylia, Cleido-cranial dysostosis, Pleonosteosis familiaris, Melorheosteosis and Multiple Rigidity of Joints. Revista Brasileiro de Cirurgia, 8, 321 .

\section{OTHER REFERENCES}

Аввott, L. C., and Saunders, J. B. de C. M. (1933): Injuries of the median nerve in fractures of the lower end of the radius. Surgery, Gynecology and Obstetrics, 57, 507.

Betrs, L. O. (1940): Morton's metatarsalgia; neuritis of the fourth digital nerve. Medical Journal of Australia, 1, 514.

Brain, W. R., Wright, A. D., and Wilkinson, M. (1947): Spontaneous compression of both median nerves in the carpal tunnel-six cases treated surgically. Lancet, 1, 277.

Cannon, B. W., and Love, J. G. (1946): Tardy median palsy; median neuritis; median thenar neuritis amenable to surgery. Surgery, 20, 210.

HARRIS, H. A. (1947): Correspondence on carpal tunnel compression of the median nerve; referring to normal age changes in the ligaments. Lancet, 1, 387 and 578.

HARRIS, W. (1926): Neuritis and Neuralgia (discussing occupational median palsy at the wrist). London: Oxford University Press.

HUNT, J. R. (1911): Thenar and hypothenar types of neural atrophy of the hand. American Journal of the Medical Sciences, 141, 224.

KinNear Wilson (1940): Neurology. London: Edward Arnold \& Co. Vol. 2, 328.

Lewis, D., and Miller, E. M. (1922): Peripheral nerve injuries associated with fractures. Transactions of the American Surgical Association, 40, 489.

Middleton, D. S. (1934) : Studies on pre-natal lesions of striated muscle as a cause of congenital deformity. Edinburgh Medical Journal, 41, 401.

Moersch, F. (1938): Median thenar neuritis. Proceedings of the Staff Meetings of the Mayo Clinic, 13, 220. Newman, P. H. (1948) : Median nerve compression in the carpal tunnel. Postgraduate Medical Journal, 24, 264. Nissen, K. I. (1948) : Plantar digital neuritis; Morton's metatarsalgia. J. of Bone and Joint Surgery, 30-B, 84. Paget, Sir James (1863): Lectures on Surgical Pathology. London: Longman, Green, Longman, Roberts and Green (median palsy from fracture of lower end of radius), 31.

RoAf, R. (1947): Correspondence on carpal tunnel compression of median nerve, reporting that it was " not uncommon" from a single injury or from overuse; and advising immobilisation in plaster. Lancet, 1, 387. Watson-Jones, R. (1943) : Fractures and Joint Injuries. Third edition. Edinburgh: E. \& S. Livingstone Ltd. (reference to carpal tunnel compression of the median nerve from haemorrhage), 116.

Woltman, H. (1941): Neuritis associated with acromegaly. Archives of Neurology and Psychiatry, 45, 680. WRIGHT, A. D. (1947): Correspondence, reporting eleven cases of carpal tunnel compression of the median nerve relieved by operation. I Lancet, $1,387$.

7.ACHARY, R. 13. (1945): Thenar palsy due to compression of the median nerve in the carpal tunnel. Surgery, Gynecology and Obstetrics, 81, 213.

vol. $31 \mathrm{~B}$, No. 4, NOVeMber 1949 